4

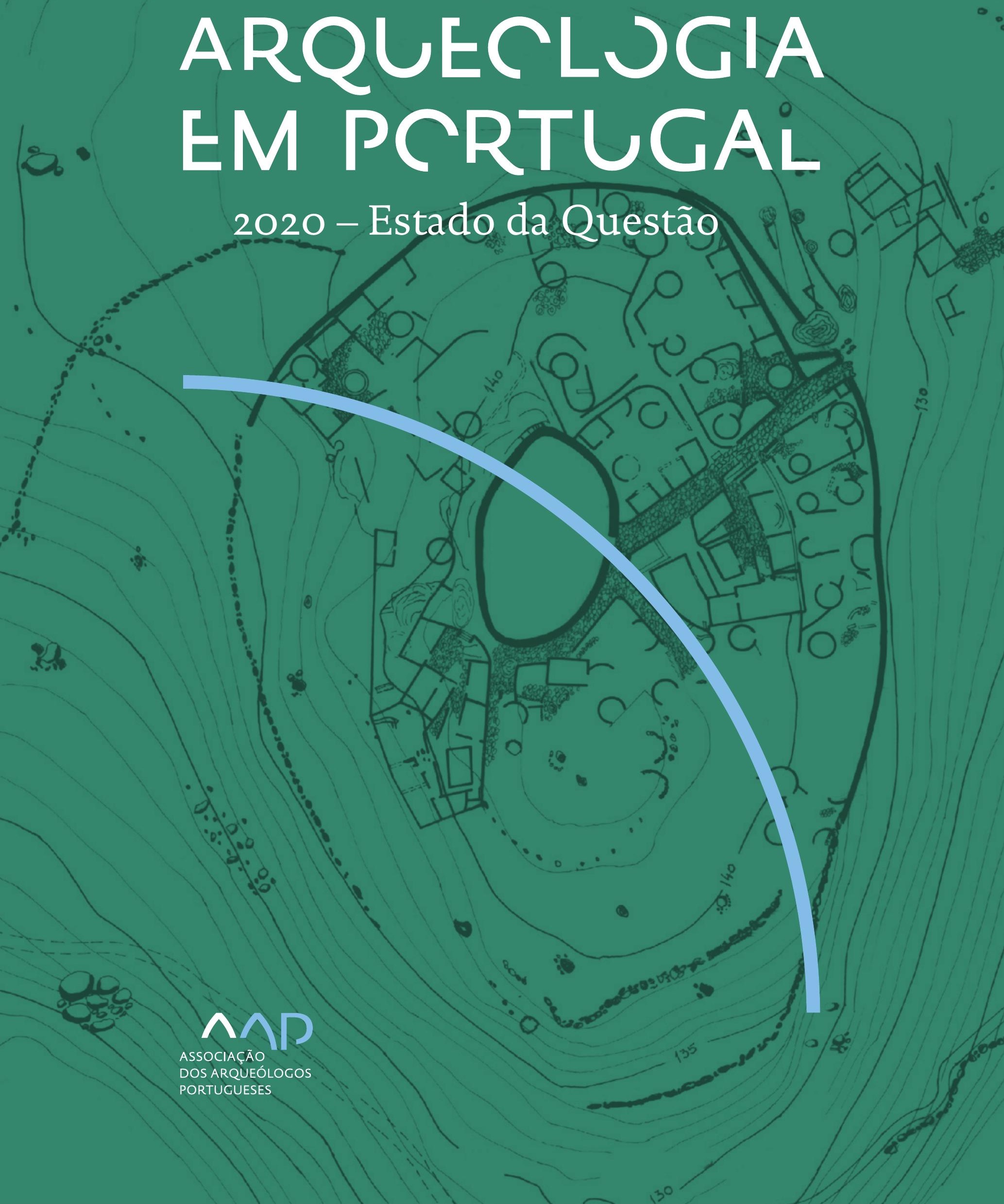


Coordenação editorial: José Morais Arnaud, César Neves e Andrea Martins Design gráfico: Flatland Design

AAP - ISBN: 978-972-9451-89-8

CITCEM - ISBN: 978-989-8970-25-1

Associação dos Arqueólogos Portugueses e CITCEM

Lisboa, 2020

O conteúdo dos artigos é da inteira responsabilidade dos autores. Sendo assim a Associação dos Arqueólogos Portugueses declina qualquer responsabilidade por eventuais equívocos ou questões de ordem ética e legal.

Desenho de capa:

Planta do castro de Monte Mozinho (Museu Municipal de Penafiel).

\section{$\hat{\wedge} \mathrm{P}$}

DOS ARQUEÓLOGOS PORTUGUESES

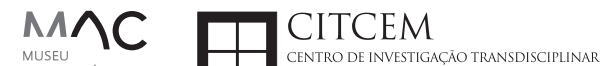
MUSEU
ARQUELLÓGICO
DO CARMO
U.PORTO

FLUP FACULDADE DE LETRAS
UNIVERSIDADE DO PORTO

Apoio

EC para a Ciência 


\section{Índice}

15 Prefácio

José Morais Arnaud

\section{Historiografia e Teoria}

17 Território, comunidade, memória e emoção: a contribuição da história da arqueologia (algumas primeiras e breves reflexões)

Ana Cristina Martins

25 Como descolonizar a arqueologia portuguesa?

Rui Gomes Coelho

41 Arqueologia e Modernidade: uma revisitação pessoal e breve de alguns aspetos da obra homónima de Julian Thomas de 2004

Vítor Oliveira Jorge

57 Dados para a História das Mulheres na Arqueologia portuguesa, dos finais do século XIX aos inícios do século XX: números, nomes e tabelas

Filipa Dimas / Mariana Diniz

73 Retractos da arqueologia portuguesa na imprensa: (in)visibilidades no feminino

Catarina Costeira / Elsa Luís

85 Arqueologia e Arqueólogos no Norte de Portugal Jacinta Bugalhão

101 Vieira Guimarães (1864-1939) e a arqueologia em Tomar: uma abordagem sobre o território e as gentes

João Amendoeira Peixoto / Ana Cristina Martins

115 Os memoráveis? A arqueologia algarvia na imprensa nacional e regional na presente centúria (2001-2019): características, visões do(s) passado(s) e a arqueologia

enquanto marca

Frederico Agosto / João Silva

129 A Evolução da Arqueologia Urbana e a Valorização Patrimonial no Barlavento Algarvio: Os casos de Portimão e Silves

Artur Mateus / Diogo Varandas / Rafael Boavida

\section{Gestão, Valorização e Salvaguarda do Património}

145 O Caderno Reivindicativo e as condições de trabalho em Arqueologia Miguel Rocha / Liliana Matias Carvalho / Regis Barbosa / Mauro Correia / Sara Simões / Jacinta Bugalhão / Sara Brito / Liliana Veríssimo Carvalho / Richard Peace / Pedro Peça / Cézer Santos

155 Os Estudos de Impacte Patrimonial como elemento para uma estratégia sustentável de minimização de impactes no âmbito de reconversões agrícolas Tiago do Pereiro

165 Salvaguarda de Património arqueológico em operações florestais: gestão e sensibilização Filipa Bragança / Gertrudes Zambujo / Sandra Lourenço / Belém Paiva / Carlos Banha / Frederico Tatá Regala / Helena Moura / Jacinta Bugalhão / João Marques / José Correia / Pedro Faria / Samuel Melro

179 Os valores do Património: uma investigação sobre os Sítios Pré-históricos de Arte Rupestre do Vale do Rio Côa e de Siega Verde José Paulo Francisco 
189 Conjugando recursos arqueológicos e naturais para potenciar as visitas ao Geoparque Litoral de Viana do Castelo (Noroeste de Portugal)

Hugo A. Sampaio / Ana M.S. Bettencourt / Susana Marinho / Ricardo Carvalhido

203 Áreas de Potencial Arqueológico na Região do Médio Tejo: Modelo Espacial Preditivo Rita Ferreira Anastácio / Ana Filipa Martins / Luiz Oosterbeek

223 Património Arqueológico e Gestão Territorial: O contributo da Arqueologia para a revisão do PDM de Avis

Ana Cristina Ribeiro

237 A coleção arqueológica do extinto Museu Municipal do Porto - Origens, Percursos e Estudos

Sónia Couto

251 Valpaços - uma nova carta arqueológica

Pedro Pereira / Maria de Fátima Casares Machado

263 Arqueologia na Cidade de Peniche

Adriano Constantino / Luís Rendeiro

273 Arqueologia Urbana: a cidade de Lagos como caso de Estudo Cátia Neto

285 Estratégias de promoção do património cultural subaquático nos Açores. O caso da ilha do Faial

José Luís Neto / José Bettencourt / Luís Borges / Pedro Parreira

297 Carta Arqueológica da Cidade Velha: Uma primeira abordagem

Jaylson Monteiro / Nireide Tavares / Sara da Veiga / Claudino Ramos / Edson Brito /

Carlos Carvalho / Francisco Moreira / Adalberto Tavares

311 Antropologia Virtual: novas metodologias para a análise morfológica e funcional Ricardo Miguel Godinho / Célia Gonçalves

\section{Didáctica da Arqueologia}

327 Como os projetos de Arqueologia podem contribuir para uma comunidade culturalmente mais consciente Alexandra Figueiredo / Claúdio Monteiro / Adolfo Silveira / Ricardo Lopes

337 Educação Patrimonial - Um cidadão esclarecido é um cidadão ativo! Ana Paula Almeida

351 A aproximação da Arqueologia à sala de aula: um caso de estudo no $3^{\circ}$ ciclo do Ensino Básico Luís Serrão Gil

363 Arqueologia 3.o - Pensar e comunicar a Arqueologia para um futuro sustentável Mónica Rolo

377 “Conversa de Arqueólogos" - Divulgar a Arqueologia em tempos de Pandemia Diogo Teixeira Dias

389 Escola Profissional de Arqueologia: desafios e oportunidades Susana Nunes / Dulcineia Pinto / Júlia Silva / Ana Mascarenhas

399 Os Museus de Arqueologia e os Jovens: a oferta educativa para o público adolescente Beatriz Correia Barata / Leonor Medeiros

411 O museu universitário como mediador entre a ciência e a sociedade: o exemplo da secção de arqueologia no Museu de História Natural e da Ciência da Universidade do Porto (MHNC-UP)

Rita Gaspar 
421 Museu de Lanifícios: Real Fábrica de Panos. Atividades no âmbito da Arqueologia Beatriz Correia Barata / Rita Salvado

427 Arqueologia Pública e o caso da localidade da Mata (Torres Novas) Cláudia Manso / Ana Rita Ferreira / Cristiana Ferreira / Vanessa Cardoso Antunes

431 Do sítio arqueológico ao museu: um percurso (também) didático Lídia Fernandes

447 Estão todos convidados para a Festa! E para dançar também... O projecto do Serviço Educativo do Museu Arqueológico do Carmo na $5^{\underline{a}}$ Edição da Festa da Arqueologia Rita Pires dos Santos

459 O “Clã de Carenque”, um projeto didático de arqueologia Eduardo Gonzalez Rocha

469 Mediação cultural: peixe que puxa carroça nas Ruínas Romanas de Troia Inês Vaz Pinto / Ana Patrícia Magalhães / Patrícia Brum / Filipa Santos

481 Didática Arqueológica, experiências do Projeto Mértola Vila Museu Maria de Fátima Palma / Clara Rodrigues / Susana Gómez / Lígia Rafael

\section{Arte Rupestre}

497 Os inventários de arte rupestre em Portugal Mila Simões de Abreu

513 O projeto FIRST-ART - conservação, documentação e gestão das primeiras manifestações de arte rupestre no Sudoeste da Península Ibérica: as grutas do Escoural e Maltravieso Sara Garcês / Hipólito Collado / José Julio García Arranz / Luiz Oosterbeek / António Carlos Silva / Pierluigi Rosina / Hugo Gomes / Anabela Borralheiro Pereira / George Nash / Esmeralda Gomes / Nelson Almeida / Carlos Carpetudo

523 Trabalhos de documentação de arte paleolítica realizados no âmbito do projeto PalæoCôa André Tomás Santos / António Fernando Barbosa / Luís Luís / Marcelo Silvestre / Thierry Aubry

537 Imagens fantasmagóricas, silhuetas elusivas: as figuras humanas na arte do Paleolítico Superior da região do Côa Mário Reis

$55^{1}$ Os motivos zoomórficos representados nas placas de tear de Vila Nova de São Pedro (Azambuja, Portugal) Andrea Martins / César Neves / José M. Arnaud / Mariana Diniz

571 Arte Rupestre do Monte de Góios (Lanhelas, Caminha). Síntese dos resultados dos trabalhos efectuados em 2007-2009 Mário Varela Gomes

599 Gravuras rupestres de barquiformes no Monte de S. Romão, Guimarães, Noroeste de Portugal Daniela Cardoso

613 Círculos segmentados gravados na Bacia do Rio Lima (Noroeste de Portugal): contributos para o seu estudo Diogo Marinho / Ana M.S. Bettencourt / Hugo Aluai Sampaio

631 Equídeos gravados no curso inferior do Rio Mouro, Monção (NW Portugal). Análise preliminar Coutinho, L.M. / Bettencourt, A.M.S / Sampaio, Hugo A.S

645 Paletas na Arte Rupestre do Noroeste de Portugal. Inventário preliminar Bruna Sousa Afonso / Ana M. S. Bettencourt / Hugo A. Sampaio 


\section{Pré-História}

661 O projeto Miño/Minho: balanço de quatro anos de trabalhos arqueológicos Sérgio Monteiro-Rodrigues / João Pedro Cunha-Ribeiro / Eduardo Méndez-Quintas / Carlos Ferreira / Pedro Xavier / José Meireles / Alberto Gomes / Manuel Santonja / Alfredo Pérez-González

677 A ocupação paleolítica da margem esquerda do Baixo Minho: a indústria lítica do sítio de Pedreiras 2 (Monção, Portugal) e a sua integração no contexto regional Carlos Ferreira / João Pedro Cunha-Ribeiro / Sérgio Monteiro-Rodrigues / Eduardo Méndez-Quintas / Pedro Xavier / José Meireles / Alberto Gomes / Manuel Santonja / Alfredo Pérez-González

693 O sítio acheulense do Plistocénico médio da Gruta da Aroeira Joan Daura / Montserrat Sanz / Filipa Rodrigues / Pedro Souto / João Zilhão

703 As sociedades neandertais no Barlavento algarvio: modelos preditivos com recurso aos SIG

Daniela Maio

715 A utilização de quartzo durante o Paleolítico Superior no território dos vales dos rios Vouga e Côa

Cristina Gameiro / Thierry Aubry / Bárbara Costa / Sérgio Gomes / Luís Luís / Carmen Manzano / André Tomás Santos

733 Uma perspetiva diacrónica da ocupação do concheiro do Cabeço da Amoreira (Muge, Portugal) a partir da tecnologia lítica Joana Belmiro / João Cascalheira / Célia Gonçalves

745 Novos dados sobre a Pré-história Antiga no concelho de Palmela. A intervenção arqueológica no sítio do Poceirão I

Michelle Teixeira Santos

757 Problemas em torno de Datas Absolutas Pré-Históricas no Norte do Alentejo Jorge de Oliveira

771 Povoamento pré-histórico nas áreas montanhosas do NO de Portugal: o Abrigo 1 de Vale de Cerdeira Pedro Xavier / José Meireles / Carlos Alves

783 Apreciação do povoamento do Neolítico Inicial na Baixa Bacia do Douro. A Lavra I (Serra da Aboboreira) como caso de estudo Maria de Jesus Sanches

797 O Processo de Neolitização na Plataforma do Mondego: os dados do Sector C do Outeiro dos Castelos de Beijós (Carregal do Sal)

João Carlos de Senna-Martinez / José Manuel Quintã Ventura / Andreia Carvalho / Cíntia Maurício

823 Novos trabalhos na Lapa da Bugalheira (Almonda, Torres Novas) Filipa Rodrigues / Pedro Souto / Artur Ferreira / Alexandre Varanda / Luís Gomes / Helena Gomes / João Zilhão

837 A pedra polida e afeiçoada do sítio do Neolítico médio da Moita do Ourives (Benavente, Portugal)

César Neves

857 Casal do Outeiro (Encarnação, Mafra): novos contributos para o conhecimento do povoamento do Neolítico final na Península de Lisboa.

Cátia Delicado / Carlos Maneira e Costa / Marta Miranda / Ana Catarina Sousa

873 Stresse infantil, morbilidade e mortalidade no sítio arqueológico do Neolítico Final/ Calcolítico ( $4^{\circ}$ e $3^{\circ}$ milénio a.C.) do Monte do Carrascal 2 (Ferreira do Alentejo, Beja) Liliana Matias de Carvalho / Sofia N. Wasterlain 
885 Come together: O Conjunto Megalítico das Motas (Monção, Viana do Castelo) e as expressões Campaniformes do Alto Minho Ana Catarina Basílio / Rui Ramos

899 Trabalhos arqueológicos no sítio Calcolítico da Pedreira do Poio Carla Magalhães / João Muralha / Mário Reis / António Batarda Fernandes

913 O sítio arqueológico de Castanheiro do Vento. Da arquitectura do sítio à arquitectura de um território João Muralha Cardoso

925 Estudo zooarqueológico das faunas do Calcolítico final de Vila Nova de São Pedro (Azambuja, Portugal): Campanhas de 2017 e 2018 Cleia Detry / Ana Catarina Francisco / Mariana Diniz / Andrea Martins / César Neves / José Morais Arnaud

943 As faunas depositadas no Museu Arqueológico do Carmo provenientes de Vila Nova de São Pedro (Azambuja): as campanhas de 1937 a 1967 Ana Catarina Francisco / Cleia Detry / César Neves / Andrea Martins / Mariana Diniz / José Morais Arnaud

959 Análise funcional de material lítico em sílex do castro de Vila Nova de S. Pedro (Azambuja, Portugal): uma primeira abordagem Rafael Lima

971 O recinto da Folha do Ouro 1 (Serpa) no contexto dos recintos de fossos calcolíticos alentejanos

António Carlos Valera / Tiago do Pereiro / Pedro Valério / António M. Monge Soares

\section{Proto-História}

987 Produção de sal marinho na Idade do Bronze do noroeste Português. Alguns dados para uma reflexão

Ana M. S. Bettencourt / Sara Luz / Nuno Oliveira / Pedro P. Simões / Maria Isabel C. Alves / Emílio Abad-Vidal

1001 A estátua-menir do Pedrão ou de São Bartolomeu do Mar (Esposende, noroeste de Portugal) no contexto arqueológico da fachada costeira de entre os rios Neiva e Cávado Ana M. S. Bettencourt / Manuel Santos-Estévez / Pedro Pimenta Simões / Luís Gonçalves

1015 O Castro do Muro (Vandoma/Baltar, Paredes) - notas para uma biografia de ocupação da Idade do Bronze à Idade Média

Maria Antónia D. Silva / Ana M. S. Bettencourt / António Manuel S. P. Silva / Natália Félix

1031 Do Bronze Final à Idade Média - continuidades e hiatos na ocupação de Povoados em Oliveira de Azeméis João Tiago Tavares / Adriaan de Man

1041 As faunas do final da Idade do Bronze no Sul de Portugal: leituras desde o Outeiro do Circo (Beja)

Nelson J. Almeida / Íris Dias / Cleia Detry / Eduardo Porfírio / Miguel Serra

1055 A Espada do Monte das Oliveiras (Serpa) - uma arma do Bronze Pleno do Sudoeste Rui M. G. Monge Soares / Pedro Valério / Mariana Nabais / António M. Monge Soares

1065 São Julião da Branca (Albergaria-a-Velha) - Investigação e valorização de um povoado do Bronze Final

António Manuel S. P. Silva / Paulo A. P. Lemos / Sara Almeida e Silva / Edite Martins de Sá

1083 Do castro de S. João ao Mosteiro de Santa Clara: notícia de uma intervenção arqueológica, em Vila do Conde Rui Pinheiro 
1095 O castro de Ovil (Espinho), um quarto de século de investigação - resultados e questões em aberto

Jorge Fernando Salvador / António Manuel S. P. Silva

1111 O Castro de Salreu (Estarreja), um povoado proto-histórico no litoral do Entre Douro e Vouga

Sara Almeida e Silva / António Manuel S. P. Silva / Paulo A. P. Lemos / Edite Martins de Sá

1127 Castro de Nossa Senhora das Necessidades (Sernancelhe): uma primeira análise artefactual Telma Susana O. Ribeiro

${ }_{1141}$ A cividade de Bagunte. O estado atual da investigação Pedro Brochado de Almeida

1153 Zoomorfos na cerâmica da Idade do Ferro no NW Peninsular: inventário, cronologias e significado Nuno Oliveira / Cristina Seoane

1163 Vasos gregos em Portugal: diferentes maneiras de contar a história do intercâmbio cultural na Idade do Ferro

Daniela Ferreira

1175 Os exotica da necrópole da Idade do Ferro do Olival do Senhor dos Mártires (Alcácer do Sal) no seu contexto regional

Francisco B. Gomes

\section{Antiguidade Clássica e Tardia}

1191 O uso de madeira como combustível no sítio da Quinta de Crestelos (Baixo Sabor): da Idade do Ferro à Romanização Filipe Vaz / João Tereso / Sérgio Simões Pereira / José Sastre / Javier Larrazabal Galarza / Susana Cosme / José António Pereira / Israel Espi

1207 Cultivos de Época Romana no Baixo Sabor: continuidade em tempos de mudança? João Pedro Tereso / Sérgio Simões Pereira / Filipe Santos / Luís Seabra / Filipe Vaz

1221 A casa romana na Hispânia: aplicação dos modelos itálicos nas províncias ibéricas Fernanda Magalhães / Diego Machado / Manuela Martins

1235 As pinturas murais romanas da Rua General Sousa Machado, n. ${ }^{5}$ 1, Chaves José Carvalho

1243 Trás do Castelo (Vale de Mir, Pegarinhos, Alijó) - Uma exploração agrícola romana do Douro

Tony Silvino / Pedro Pereira

1255 A sequência de ocupação no quadrante sudeste de Bracara Augusta: as transformações de uma unidade doméstica Lara Fernandes / Manuela Martins

1263 Os Mosaicos com decoração geométrica e geométrico-vegetalista dos sítios arqueológicos da área do Conuentus Bracaraugustanus. Novas abordagens quanto à conservação, restauro, decoração e datação Maria de Fátima Abraços / Licínia Wrench

1277 “Casa Romana” do Castro de São Domingos (Cristelos, Lousada): Escavação, Estudo e Musealização Paulo André de P. Lemos

1291 A arqueobotânica no Castro de Guifões (Matosinhos, Noroeste de Portugal): O primeiro estudo carpológico

Luís Seabra / Andreia Arezes / Catarina Magalhães / José Varela / João Pedro Tereso 
1305 Um Horreum Augustano na Foz do Douro (Monte do Castelo de Gaia, Vila Nova de Gaia) Rui Ramos

1311 Ponderais romanos na Lusitânia: padrões, formas, materiais e contextos de utilização Diego Barrios Rodríguez

1323 Um almofariz centro-itálico na foz do Mondego

Marco Penajoia

1335 Estruturas romanas de Carnide - Lisboa Luísa Batalha / Mário Monteiro / Guilherme Cardoso

1347 O contexto funerário do sector da "necrópole NO" da Rua das Portas de S. Antão (Lisboa): o espaço, os artefactos, os indivíduos e a sua interconectividade na interpretação do passado Sílvia Loja, José Carlos Quaresma, Nelson Cabaço, Marina Lourenço, Sílvia Casimiro, Rodrigo Banha da Silva, Francisca Alves-Cardoso

${ }_{1361}$ Povoamento em época Romana na Amadora - resultados de um projeto pluridisciplinar Gisela Encarnação / Vanessa Dias

1371 A Arquitectura Residencial em Mirobriga (Santiago do Cacém): contributo a partir de um estudo de caso Filipe Sousa / Catarina Felício

${ }_{1385}$ O fim do ciclo. Saneamento e gestão de resíduos nos edifícios termais de Mirobriga (Santiago do Cacém)

Catarina Felício / Filipe Sousa

1399 Balsa, Topografia e Urbanismo de uma Cidade Portuária Vítor Silva Dias / João Pedro Bernardes / Celso Candeias / Cristina Tété Garcia

1413 No Largo das Mouras Velhas em Faro (2017): novas evidências da necrópole norte de Ossonoba e da sua ocupação medieval Ricardo Costeira da Silva / Paulo Botelho / Fernando Santos / Liliana Nunes

1429 Instrumentos de pesca recuperados numa fábrica de salga em Ossonoba (Faro) Inês Rasteiro / Ricardo Costeira da Silva / Paulo Botelho

1439 A Necrópole Romana do Eirô, Duas Igrejas (Penafiel): intervenção arqueológica de 2016 Laura Sousa / Teresa Soeiro

1457 Ritual, descarte ou afetividade? A presença de Canis lupus familiaris na Necrópole Noroeste de Olisipo (Lisboa)

Beatriz Calapez Santos / Sofia Simões Pereira / Rodrigo Banha da Silva / Sílvia Casimiro / Cleia Detry / Francisca Alves Cardoso

1467 Dinâmicas económicas em Bracara na Antiguidade Tardia Diego Machado / Manuela Martins / Fernanda Magalhães / Natália Botica

1479 Cerâmicas e Vidros da Antiguidade Tardia do Edifício sob a Igreja do Bom Jesus (Vila Nova de Gaia) Joaquim Filipe Ramos

1493 Novos contributos para a topografia histórica de Mértola no período romano e na Antiguidade Tardia Virgílio Lopes

\section{8. Época Medieval}

1511 Cerâmicas islâmicas no Garb setentrional "português": algumas evidências e incógnitas Constança dos Santos / Helena Catarino / Susana Gómez / Maria José Gonçalves / Isabel Inácio / Gonçalo Lopes / Jacinta Bugalhão / Sandra Cavaco / Jaquelina Covaneiro / Isabel Cristina Fernandes / Ana Sofia Gomes 
1525 Contributo para o conhecimento da cosmética islâmica, em Silves, durante a Idade Média Rosa Varela Gomes

1537 Yábura e o seu território - uma análise histórico-arqueológica de Évora entre os séculos VIII-XII José Rui Santos

1547 A encosta sul do Castelo de Palmela - resultados preliminares da escavação arqueológica Luís Filipe Pereira / Michelle Teixeira Santos

1559 A igreja de São Lourenço (Mouraria, Lisboa): um conjunto de silos e de cerâmica medieval islâmica

Andreia Filipa Moreira Rodrigues

1571 O registo material de movimentações populacionais no Médio Tejo, durante os séculos XII-XIII. Dois casos de "sunken featured buildings", nos concelhos de Cartaxo e Torres Novas Marco Liberato / Helena Santos / Nuno Santos

1585 O nordeste transmontano nos alvores da Idade média. Notas para reflexão Ana Maria da Costa Oliveira

1601 Sepulturas escavadas na rocha do Norte de Portugal e do Vale do Douro: primeiros resultados do Projecto SER-NPVD

Mário Jorge Barroca / César Guedes / Andreia Arezes / Ana Maria Oliveira

1619 "Portucalem Castrum Novum" entre o Mediterrâneo e o Atlântico: o estudo dos materiais cerâmicos alto-medievais do arqueossítio da rua de D. Hugo, nํ. 5 (Porto) João Luís Veloso

1627 A Alta Idade Média na fronteira de Lafões: notas preliminares sobre a Arqueologia no Concelho de Vouzela

Manuel Luís Real / Catarina Tente

1641 Um conjunto cerâmico medieval fora de portas: um breve testemunho aveirense Susana Temudo

${ }_{1651}$ Os Lóios do Porto: uma perspetiva integrada no panorama funerário da Baixa Idade Média à Época Moderna em meios urbanos em Portugal

Ana Lema Seabra

1659 O Caminho Português Interior de Santiago como eixo viário na Idade Média Pedro Azevedo

1665 Morfologia Urbana: Um exercício em torno do Castelo de Ourém André Donas-Botto / Jaqueline Pereira

1677 Intervenção arqueológica na Rua Marquês de Pombal/Largo do Espírito Santo (Bucelas, Loures)

Florbela Estêvão / Nathalie Antunes-Ferreira / Dário Ramos Neves / Inês Lisboa

1691 O Cemitério Medieval do Poço do Borratém e a espacialidade funerária na cidade de Lisboa Inês Belém / Vanessa Filipe / Vasco Noronha Vieira / Sónia Ferro / Rodrigo Banha da Silva

1705 Um Espaço Funerário Conventual do séc. XV em Lisboa: o caso do Convento de São Domingos da Cidade Sérgio Pedroso / Sílvia Casimiro / Rodrigo Banha da Silva / Francisca Alves Cardoso

\section{9. Época Moderna e Contemporânea}

1721 Arqueologia Moderna em Portugal: algumas reflexões críticas em torno da quantificação de conjuntos cerâmicos e suas inferências históricas e antropológicas Rodrigo Banha da Silva / André Bargão / Sara da Cruz Ferreira

1733 Faianças de dois contextos entre os finais do século XVI e XVIII do Palácio dos Condes de Penafiel, Lisboa

Martim Lopes / Tomás Mesquita 
1747 Um perfil de consumo do século XVIII na foz do Tejo: O caso do Mercado da Ribeira, Lisboa Sara da Cruz Ferreira / Rodrigo Banha da Silva / André Bargão

1761 Os Cachimbos dos Séculos XVII e XVIII do Palácio Mesquitela e Convento dos Inglesinhos (Lisboa)

Inês Simão / Marina Pinto / João Pimenta / Sara da Cruz Ferreira / André Bargão / Rodrigo Banha da Silva

1775 "Tomar os fumos da erua que chamão em Portugal erua sancta». Estudo de Cachimbos provenientes da Rua do Terreiro do Trigo, Lisboa

Miguel Martins de Sousa / José Pedro Henriques / Vanessa Galiza Filipe

1787 Cachimbos de Barro Caulínitico da Sé da Cidade Velha (República de Cabo Verde)

Rodrigo Banha da Silva / João Pimenta / Clementino Amaro

1801 Algumas considerações sobre espólio não cerâmico recuperado no Largo de Jesus (Lisboa) Carlos Boavida

1815 Adereços de vidro, dos séculos XVI-XVIII, procedentes do antigo Convento de Santana de Lisboa (anéis, braceletes e contas)

Joana Gonçalves / Rosa Varela Gomes / Mário Varela Gomes

1837 Da ostentação, luxo e poder à simplicidade do uso quotidiano: arqueologia e simbologia de joias e adornos da Idade Moderna Portuguesa Jéssica Iglésias

1849 Os amuletos em Portugal - dos objetos às superstições: o coral vermelho Alexandra Vieira

1865 Cerâmicas de Vila Franca de Xira nos séculos XV e XVI Eva Pires

1879 «Não passa por teu o que me pertence». Marcas de individualização associadas a faianças do Convento de Nossa Senhora de Aracoeli, Alcácer do Sal Catarina Parreira / Íris Fragoso / Miguel Martins de Sousa

1891 Cerâmica de Leiria: alguns focos de produção

Jaqueline Pereira / André Donas-Botto

1901 Os Fornos na Rua da Biquinha, em Óbidos Hugo Silva / Filipe Oliveira

1909 A casa de Pêro Fernandes, contador dos contos de D. Manuel I: o sítio arqueológico da Silha do Alferes, Seixal (século XVI) Mariana Nunes Ferreira

1921 O Alto da Vigia (Sintra) e a vigilância e defesa da costa Alexandre Gonçalves / Sandra Santos

1937 O contexto da torre sineira da Igreja de Santa Maria de Loures Paulo Calaveira / Martim Lopes

1949 A Necrópole do Hospital Militar do Castelo de São Jorge e as práticas funerárias na Lisboa de Época Moderna Susana Henriques / Liliana Matias de Carvalho / Ana Amarante / Sofia N. Wasterlain

1963 SAND - Sarilhos Grandes Entre dois Mundos: o adro da Igreja e a Paleobiologia dos ossos humanos recuperados

Paula Alves Pereira / Roger Lee Jesus / Bruno M. Magalhães

1975 Expansão urbana da vila de Cascais no século XVII e XVIII: a intervenção arqueológica na Rua da Vitória no 15 a 17

Tiago Pereira / Vanessa Filipe

1987 Novos dados para o conhecimento do Urbanismo de Faro em época Moderna Ana Rosa 
1995 Um exemplo de Arqueologia Urbana em Alcoutim: o Antigo Edifício dos CTT Marco Fernandes / Marta Dias / Alexandra Gradim / Virgílio Lopes / Susana Gómez Martínez

2007 Palácio dos Ferrazes (Rua das Flores/Rua da Vitória, Porto): a cocheira de Domingos Oliveira Maia

Francisco Raimundo

2021 As muitas vidas de um edifício urbano: História, Arqueologia e Antropologia no antigo Recreatório Paroquial de Penafiel Helena Bernardo / Jorge Sampaio / Marta Borges

2035 O convento de Nossa Senhora da Esperança de Ponta Delgada: o contributo da arqueologia para o conhecimento de um monumento identitário João Gonçalves Araújo / N’Zinga Oliveira

2047 Arqueologia na ilha do Corvo... em busca da capela de Nossa Senhora do Rosário Tânia Manuel Casimiro / José Luís Neto / Luís Borges / Pedro Parreira

2059 Perdidos à vista da Costa. Trabalhos arqueológicos subaquáticos na Barra do Tejo Jorge Freire / José Bettencourt / Augusto Salgado

2071 Arqueologia marítima em Cabo Verde: enquadramento e primeiros resultados do projecto CONCHA

José Bettencourt / Adilson Dias / Carlos Lima / Christelle Chouzenoux / Cristóvão Fonseca / Dúnia Pereira / Gonçalo Lopes / Inês Coelho / Jaylson Monteiro / José Lima / Maria Eugénia Alves / Patrícia Carvalho / Tiago Silva

2085 Trabalhos arqueológicos na Cidade Velha (Ribeira Grande de Santiago, Cabo Verde): reflexões sobre um projecto de investigação e divulgação patrimonial André Teixeira / Jaylson Monteiro / Mariana Mateus / Nireide Tavares / Cristovão Fonseca / Gonçalo C. Lopes / Joana Bento Torres / Dúnia Pereira / André Bargão / Aurélie Mayer / Bruno Zélie / Carlos Lima / Christelle Chouzenoux / Inês Henriques / Inês Pinto Coelho / José Lima / Patrícia Carvalho / Tiago Silva

2103 A antiga fortificação de Quelba / Khor Kalba (E.A.U.). Resultados de quatro campanhas de escavações, problemáticas e perspectivas futuras Rui Carita / Rosa Varela Gomes / Mário Varela Gomes / Kamyar Kamyad

2123 Colónias para homens novos: arqueologia da colonização agrária fascista no noroeste ibérico Xurxo Ayán Vila / José Mạ . Señorán Martín 


\title{
OS VALORES DO PATRIMÓNIO: UMA INVESTIGAÇÃO SOBRE OS SÍTIOS PRÉ-HISTÓRICOS DE ARTE RUPESTRE DO VALE DO RIO CÔA E DE SIEGA VERDE
}

\author{
José Paulo Francisco
}

\begin{abstract}
RESUMO
Apresentação do projecto de investigação de doutoramento Os Valores do Património: uma investigação sobre os sítios pré-históricos de arte rupestre do Vale do Rio Côa e de Siega Verde, em curso na Faculdade de Geografia e História da Universidade de Barcelona, sob a orientação da Professora Margarita Díaz-Andreu. Sintetizam-se as perguntas de investigação e os objectivos gerais e específicos, à luz das convenções e recomendações da Unesco para os sítios integrados na Lista do Património Mundial. A arte rupestre do Vale do Côa foi incluída nessa lista em 1998, tendo a área sido alargada às manifestações artísticas de Siega Verde em 2010. Palavras-chave: Arte rupestre, Metodologia, Vale do Côa, Património, Legislação do património.
\end{abstract}

\begin{abstract}
Presentation of the $\mathrm{PhD}$ research project Heritage values: research into Pre-historic rock art sites of the Côa River Valley and Siega Verde, to be developed at the Geography and History Faculty of the University of Barcelona, under supervisionof ProfessorMargaritaDíaz-Andreu. The author summarises the research questions and general and specific objectives under the scope of Unesco conventions and recommendations for World Heritage sites. The rock art of the Côa Valley has been part of that list since 2007, whereas the artistic manifestations of Siega Verde were considered an integral part of the same area from 2010.
\end{abstract} Keywords: Rock art, Methodology, Côa Valley, Heritage, Legislation on heritage.

\section{INTRODUÇÃO}

Porque conservamos o património e para quem? Esta é a pergunta que esta tese de doutoramento pretende responder no contexto dos Sítios Pré-históricos de Arte Rupestre do Vale do Rio Côa e de Siega Verde. O interesse, da identificação e avaliação dos valores patrimoniais que levaremos a cabo nesta tese de doutoramento, reside na compreensão dos Sítios de Arte Rupestre do Vale do Rio Côa e de Siega Verde como fenómeno social e na hipótese de construção de uma proposta de plano de gestão destes bens patrimoniais com base nos valores identificados, que valorize o papel das Comunidades, conforme os objectivos estratégicos da Convenção do Património Mundial, "The "fifth C" for "Communities" (o quinto "C", significando este C Comunidade e sendo os outros quatro: Credibilidade; Conservação; Capacidade e Comunicação (Albert, 2012); (UNESCO, 2007: 193).

\section{OBJECTIVO GERAL, ESPECÍFICOS E PERGUNTAS DE INVESTIGAÇÃO}

O objectivo geral desta investigação é analisar o valor social dos Sítios Pré-históricos de Arte Rupestre do Vale do Rio Côa e de Siega Verde. Gerar conhecimento sobre o que significaram e geraram, em termos sociais desde a sua descoberta até à actualidade e contrastar o modelo de gestão actual destes sítios, com o estabelecido, nas Orientações Técnicas para a Aplicação da Convenção do Património Mundial, no respeitante à participação social.

1. Arqueólogo, membro do Grup d’Arqueologia Pública i Patrimoni Universitat de Barcelona: http://www.gapp.cat/ Facultat de Filosofia i de Geografía e Història, Carrer Montalegre 6, o8oo1, Barcelona; josepaulofrancisco32@gmail.com 


\subsection{Objectivos específicos}

Os objectivos específicos são:

1. Identificar e analisar os valores patrimoniais actuais dos Sítios Pré-históricos de Arte Rupestre do Vale do Rio Côa e de Siega Verde.

2. Analisar se existiram mudanças nos valores do património ao longo do último século.

3. Estudar como os valores patrimoniais são per- cebidos pelos diferentes actores.

a) Pelos responsáveis pelas políticas públicas.

b).Pelas comunidades locais.

c)Por outros grupos.

4. Realizar um estudo da importância da tipologia de valores identificados no âmbito dos diversos grupos, com especial ênfase no valor social.

5. Ver como as novas directivas da UNESCO para fomentar a participação social estão a ser percebidas e implementadas: pelos gestores e pelas comunidades.

6. Perceber quais são os elementos relacionados com os valores do património que deveriam constar num Plano de Gestão dos Sítios Pré-históricos de Arte Rupestre do Vale do Rio Côa e de Siega Verde.

\subsection{Perguntas de investigação}

Os objectivos mencionados, têm como desiderato, responder às seguintes perguntas de investigação:

1. O que significaram e significam os Sítios Préhistóricos de Arte Rupestre do Vale do Rio Côa e de Siega Verde, em termos sociais, desde a sua descoberta até à actualidade?

2. Qual o impacto social ao nível local da sua inscrição na Lista do Património Mundial?

3. Em que âmbitos as comunidades locais participam na gestão deste bem cultural transfronteiriço?

4. São os valores do património identificados considerados na gestão dos sítios?

5. Quais são os valores do património, que deveriam constar num Plano de Gestão dos Sítios Pré-históricos de Arte Rupestre do Vale do Rio Côa e de Siega Verde?

\subsection{Importância deste trabalho}

A importância deste trabalho de investigação, reside na necessidade de aplicação do conceito de valores do património nos estudos do património arqueológico, uma prática interdisciplinar e transdisciplinar que pretende caracterizar os processos históricos e sociais gerados em torno dos bens patrimoniais. A prática actual da gestão do património, considera a gestão baseada nos valores como um dos enfoques mais importantes da gestão do património arqueológico (Austrália ICOMOS, 2000; Johnston et al., 2006; Aplin, 2002; Doumas, 2013; de la Torre, 2013). A identificação e avaliação dos valores patrimoniais dos sítios arqueológicos deste caso de estudo (Pearson \& Sullivan, 1995: 126; Lung et al., 2007) contribuirá para uma proposta de Plano de Gestão, tendo por base o pressuposto de que a marginalização de alguns valores e a supremacia de outros pode diminuir o significado de um lugar (Mason, 1999). Na actualidade a gestão dos sítios classificados como Património Mundial pela UNESCO, exige a identificação e avaliação dos valores atribuídos a estes sítios pelas diferentes partes interessadas (Carter \& Bramley, 2002; Feilden \& Jokileht, 1993; Mydland \& Grahn, 2012). Face a inexistência de um Plano de Gestão dos Sítios Pré-Históricos de Arte Rupestre do Vale do Rio Côa e de Siega Verde, a identificação e avaliação dos seus valores patrimoniais pode contribuir para a elaboração desse plano.

\section{CONTEXTO DA INVESTIGAÇÃO}

A importância que a sociedade atribui ao património cultural tem vindo a alterar-se, ao seu valor identitário, acresce hoje o valor social e económico enquanto recurso territorial gerador de fortes contributos para as economias locais e regionais, nomeadamente, no contexto do turismo patrimonial. No entanto são ainda escassos os estudos de impacto social e económico aplicados ao património cultural que o comprovem, inexistentes para o nosso caso de estudo. Esta investigação em Arqueologia Pública, visa obter uma visão da percepção e valor social destes elementos do património arqueológico, classificados como Património Mundial pela UNESCO. Medir o retorno sociocultural e económico do investimento realizado nas acções de investigação, conservação e patrimonialização, o impacto social e económico do seu estatuto de Património Mundial e do turismo patrimonial nas comunidades locais e analisar a sustentabilidade das práticas de gestão com base nos valores identificados.

A identificação e avaliação dos valores patrimoniais dos Sítios Pré-Históricos de Arte Rupestre do Vale do Rio Côa e de Siega Verde e o impacto das actividades arqueológicas sobre os cidadãos, permi- 
tirá estudar o próprio valor social da arqueologia. O papel do arqueólogo na atribuição de valores do património, pode ser encontrado no conteúdo dos códigos de conduta das associações profissionais de arqueologia, que emergiram no contexto da gestão de património a partir dos anos 6o (para uma visão geral, ver, por exemplo, Aitchison, 2007; Meskell \& Pels, 2005; Lynott \& Wylie, 2000). Em todos esses códigos, os arqueólogos são considerados "os principais conselheiros sobre os valores do património" (Okamura, 2010: 58).

\subsection{Os valores do património}

No início do século XX, o conceito de valor tornou-se cada vez mais importante no campo da conservação, Alois Riegl (1903) na sua obra O Culto Moderno dos Monumentos, investigou o papel dos diferentes valores no contexto da conservação, descreve diferentes tipos de valor que servem para orientar a ação para as intervenções de conservação. Riegl defende a existência de um afastamento entre o autor e o espectador das diferentes épocas “... o sentido e a importância dos monumentos não cabem às próprias obras em virtude da sua determinação originária, mas somos nós, modernos, quem lhos atribui" (Riegl, 2013; 14). Enquanto Ruskin e Viollet-le-Duc, enfatizam uma abordagem específica para a conservação baseada na importância da idade e integridade, respectivamente, Riegl teoriza a conservação sistematicamente com base na ideia de valor.

A prevalência de um determinado tipo de valor serve, para explicar por que certas intervenções são preferidas em detrimento de outras (Herrmann, 2015: 115). Na primeira metade da década de 1980, Tainter e Lucas (Tainter \& Lucas, 1983) e Lipe (Lipe, 1984) abordaram a questão da importância da investigação sobre a gestão de recursos culturais, destacaram a ideia de qualidade em relação à "significância" e "valor e significado", ou seja, a noção de valor como guia para a selecção (Herrmann, 2015: 117-118).

O termo "valores patrimoniais" refere-se aos significados e valores que os indivíduos e grupos de pessoas concedem ao património (Díaz-Andreu, 2016 $\mathrm{a}$; b; 2017). Os valores patrimoniais podem ser definidos como um conjunto de características ou qualidades objectos e locais culturais, e práticas culturais intangíveis percebidas como positivas por certos indivíduos ou grupos (Díaz-Andreu, no prelo). Os valores do património não são fixos, mas criados culturalmente (Díaz-Andreu, no prelo), existem vários tipos de valor, histórico, estético, natural, antropológico, simbólico, social e económico entre outros, sendo de relevar a importância atribuída nas últimas quatro décadas ao valor social "um apego colectivo a um lugar que incorpora significados e valores que são importantes para uma comunidade ou comunidades" (Jones, 2017: 22).

Para uma avaliação dos valores dos sítios arqueológicos e patrimoniais, precisamos considerar a relevância dos valores artísticos, históricos e sociais que estes sítios geram, tal realização requer o envolvimento das partes interessadas como bens compartilhados que são e não vistos como bens públicos ou de mercado (Klamer, 2014: 59). Os estudos de impacto económico servem para avaliar os valores financeiros gerados por um museu, um sítio arqueológico, avaliam o retorno económico das actividades económicas geradas (Klamer, 2014: 61). Os valores culturais de um sítio arqueológico compreendem os seus aspectos artísticos, históricos, estéticos, valores espirituais, valores sociais e dizem respeito à sociedade em geral, os valores pessoais são os valores que um sítio arqueológico e patrimonial pode ter para uma pessoa, os valores podem variar entre os stakeholders, as crianças tendem a ter interesses que pode ser bastante diferente dos adultos (Klamer, 2014: 64-65).

No período de 1998 até 2005, o Getty Conservation Institute (GCI) desenvolveu uma investigação denominada "Research on the Values of Heritage", dedicada aos valores do património, visava estabelecer vínculos entre as abordagens culturais e económicas de valorização do património. Desta investigação resultou a publicação de um conjunto de publicações de referência, Economics and Heritage Conservation:A Meeting Organized by the Getty Conservation Institute (Mason, 1999), resultante de um encontro ocorrido em Dezembro de 1998, em Los Angeles, e publicado em 1999: Values and Heritage Conservation:Research Report (Avrami, Mason, \& de la Torre, 2000), no ano 2000 e Assessing the Values of Cultural Heritage: Research Repor (de la Torre, 2002), em 2002. Um dos pontos a relevar do encontro de 1998, seria a preocupação com a crescente valoração do património em termos do valor económico, em detrimento de outras abordagens de avaliação e a constatação de que os métodos utilizados seriam insuficientes para identificar os vários valores do património. Outra conclusão relevante deste encontro foi a compreensão da noção essen- 
cialmente pública e colectiva do património, desta forma, percebe-se ainda mais a necessidade de melhor compreendermos os processos sociais envolv dos na valorização do património, com o objectivo de estender os múltiplos valores atribuídos ao património cultural, nomeadamente aos valores patrimoniais dos sítios arqueológicos.

No entanto o termo "valor" poderia ser substituído pelo termo "significância" (Austrália, ICOMOS: 2000). A Significância, segundo Mason (Mason, 2002), é "construída e modelada pelo tempo, lugar e pessoas envolvidas na sua articulação" indica a importância geral de um sítio, determinada através da análise da totalidade dos valores que lhe são atribuídos, reflecte o grau de importância do lugar (Mason \& Avrami, 2002), pode ser vista como uma definição mais ampla do que os valores do património (Mason, 2002) correspondentes às diferentes partes interessadas (Doumas, 2013; de la Torre, 2013). Mason e Avrami (2002:16-17) sugerem sete grupos de valores na avaliação de significância: valor histórico e artístico; valor social e cívico; valor espiritual ou religioso; valor simbólico ou de identidade; valor científico; valor natural; valor económico.

Outra questão importante em relação à compreensão dos valores patrimoniais é a origem conceptual dos valores, os valores são intrínsecos, isto é, objectivos e corporificados no objecto patrimonial; ou só existem em relação a outra coisa, são extrínsecos, isto é, subjectivos e atribuído pelas pessoas. Estas duas perspectivas estão ligadas às ideias de valor universal e representativo. Com o crescente reconhecimento da diversidade cultural, o conceito de valor patrimonial foi além do intrínseco e universal e foi reconhecida a natureza extrínseca e relativa dos valores, relevando o papel central das pessoas e comunidades na definição do património e dos seus valores.

$\mathrm{O}$ valor é assim determinado pela cognição e pelo contexto, é relacional, esta perspectiva construtivista foi confirmada na investigação do Getty Conservation Institute na segunda metade da década de 1990 (Herrmann, 2015: 119-122). Na maior parte dos casos, os valores patrimoniais não são intrínsecos, mas sim subjectivos, ligados ao contexto, não é apenas o especialista que identifica os valores do património, mas as várias partes interessadas envolvidas e que se interessam pelo património, as comunidades locais. Desta forma o "valor universal excepcional" dos sítios inscritos na Lista do Património Mundial da UNESCO deve ser gerido por forma a considerar os valores do lugar para as comunidades locais. Os valores do património nãos são um conceito imutável (Taylor, 2004) são uma construção cultural e social (Darvill, 1995; Mason, 2006; Hall, 1997; Heras et al., 2013).

A tipologia dos valores do património tem sido objecto de debate nos últimos anos (Matarasso, 1997; Williams, 1997; Sandell, 1998; Persson, 2000; Sheppard, 2000; Evans, 2001; Parker, 2002; Frey, 1997; Russell \& Winkworth, 2001; de la Torre, 2013; Mason \& Avrami, 2002; English Heritage, 2006). Existem diferentes tipos de valores patrimoniais, a mais antiga classificação sistemática conhecida no campo da conservação foi feita por Aloise Riegl em 1903 na sua obra "O Culto Moderno dos Monumentos" (Riegl, 2013), um estudo tipológico sobre os valores artísticos e históricos da arte e arquitectura. A tipologia de Riegl incluía o: valor artístico, valor histórico, valor de antiguidade, valor comemorativo e valor actual, discute a diferença entre valores memoriais e actuais. Recentemente outras tipologias foram criadas (Labadi, 2007, 2013; Mason, 2008; Battaini-Dragoni, 2005).

Outra classificação realizada por Lipe (Lipe,1984) identifica o valor económico, estético, associativo e simbólico, baseada na ideia de contexto (no âmbito da investigação encomendada pelo Getty Institute, a ideia de contexto foi reforçada), distingue quatro contextos de valor e os seus tipos associados: o potencial económico é expresso em valor económico; a tradição estilística, psicologia humana e outros factores influenciam os padrões estéticos, sendo, o valor estético e o conhecimento tradicional, que se manifestam, por exemplo, em documentos históricos, tradições orais e mitologia, que determinam o valor associativo ou simbólico. A Carta de Veneza, considera o valor histórico, arqueológico e valor estético enquanto a Convenção do Património Mundial os valores: histórico, artístico, científico, estético, etnológico ou antropológico, e além desses considera ainda o valor social (Herrmann, 2015: 124-125). Os valores desempenham um papel central nos estudos do património, desde da década de setenta do século XX. Desde esse momento, assistimos a uma crescente importância da avaliação e gestão dos diversos valores do património, com o interesse pós-moderno na construção social do património, o foco vais mais além dos valores intrínsecos e a natureza "extrínseca "dos valores do património tem sido considerada, ou seja, o entendimento de que os 
valores são construídos por indivíduos e grupos de pessoas (Herrmann, 2015: 116-117). Várias tipologias de valores têm sido propostas, mas, no entanto, as classificações são subjectivas e dependentes das perspectivas dos especialistas ou do contexto da investigação.

Os relatórios sobre valor e economia do património cultural organizados pelo Getty Conservation Institute, no âmbito da investigação "Research on the Values of Heritage" acrescentam que o termo valor é entendido e utilizado para nos referirmos às "qualidades e características vistas nas coisas" e varia amplamente do valor estético ou simbólico ao económico (Herrmann, 2015: 116-117). Distinguem os conceitos de valor e significado, sendo que o "significado cultural", é entendido como um termo abrangente para o conjunto de valores atribuídos a um sítio. Em termos práticos conduziram a uma (re)teorização do conceito de conservação dos monumentos e sítios, de um mero foco no aspecto material das intervenções para a gestão de valores patrimoniais.

\subsection{Natureza do valor de património}

O valor é assim determinado pela cognição e pelo contexto, é relacional, esta perspectiva construtivista foi confirmada na investigação do Getty Conservation Institute (Herrmann, 2015: 119-122). Na maior parte dos casos, os valores patrimoniais não são intrínsecos, mas sim subjectivos, ligados ao contexto, não é apenas o especialista que identifica os valores do património, mas as várias partes interessadas envolvidas e que se interessam pelo património, as comunidades locais. Desta forma o valor universal dos sítios inscritos na Lista do Património Mundial da UNESCO deve ser gerido por forma a considerar os valores do lugar para as comunidades locais. Os valores do património nãos são um conceito imutável (Taylor, 2004) são uma construção cultural e social (Darvill, 1995; Mason, 2006; Hall, 1997; Heras et al., 2013).

\subsection{Valor social do património}

O valor social do património é um conceito complexo (Pearson \& Sullivan, 1995: 155), tem sido utilizado de diversas maneiras: identidade da comunidade; apego ao lugar; valor simbólico; associações espirituais; capital social; lazer; e educação (Jones \& Leech, 2015: 6, Jones, $2016 \&$ 2017). A terminologia inclui além do "valor social" conceitos sobrepostos como "valor comunitário" (Pearson \& Sullivan, 1995), "valor comunal" (English Heritage, 2008), "valor da comunidade patrimonial" (Conselho da Europa, 2005 \& 2009) e "significado social" (Bryne et al., 2003) usados para designar aspectos do que é descrito como valor social. A tipologia de valores patrimoniais considerados pelos especialistas ao longo dos últimos dois séculos, mostra a consideração inicial dos valores históricos e estéticos, a inclusão nos finais do século XIX do valor natural e antropológico e a importância atribuída ao valor histórico, a par do artístico e valor de antiguidade.

As Cartas Internacionais produzidas no século XX privilegiaram os valores históricos, científicos e estéticos, juntamente com a ênfase no tecido histórico (por exemplo, Carta de Atenas, 1931; Carta de Veneza, 1964). Só na segunda metade do século XX desde a reunião do ICOMOS realizada em Burra no ano de 1979 (ICOMOS Australia,1979), assistimos à assunção do valor social do património e à necessidade de avaliação do significado do lugar, ou seja, à análise dos valores do lugar além do seu valor de uso. A Carta para a Conservação dos Locais de Importância Cultural, Carta de Burra - The Australia ICOMOS Guidelines for the Conservation of Places of Cultural Significance de 1979 (cuja última atualização foi realizada em 2013), foi adoptada pelo ICOMOS-Austrália neste momento e posteriormente revista em 1981, 1988, 1999 e 2013. Colocou a avaliação do "significado cultural" no centro do processo de conservação com base no seguinte pressuposto: "lugares de significado cultural enriquecem a vida das pessoas, muitas vezes proporcionando um profundo e inspirador senso de conexão com a comunidade e a paisagem e com as experiências vividas" (ICOMOS Austrália, 1979: 1). O valor social é definido nas Directrizes da Carta de Burra como "as qualidades pelas quais um lugar se tornou um foco espiritual, político, nacional ou outro sentimento cultural", é assim colocado em pé de igualdade, pelo menos em teoria, com o valor histórico, estético, cultural e científico (ICOMOS Austrália, 2013). Este documento apresenta a noção de significado cultural, onde se encontram valores como os históricos, estéticos, científicos e sociais.

\section{METODOLOGIAS DE INVESTIGAÇÃO}

Nesta investigação aplicaremos a metodologia antropológica ou etnográfica aplicada à arqueologia. As abordagens desde as etnografias arqueológicas 
oferecem informações importantes sobre a multivocalidade e os discursos gerados sobre os sítios arqueológicos e para a tomada de decisões na gestão de património (Castañeda \& Matthews, 2008; Geurds, 2007; Hamilakis \& Anagnostopoulis, 2009; van der Linde, 2012). A etnografia arqueológica pode ser definida como um espaço transdisciplinar e transcultural que permite a interacção entre os investigadores e diversos públicos (Hamilakis \& Anagnostopoulis, 2009). Constitui um método reflexivo para investigar o que a arqueologia faz na sociedade (Smith, 2004: 1), tem as suas origens nas arqueologias pós-processuais interpretativas dos anos 80 e 90 do século XX e na ideia de que as interpretações do passado são socialmente construídas, multivocais e politicamente influenciadas (van der Linde, 2012: 25). $\mathrm{Na}$ última década surgiram estudos que aplicaram o método etnográfico em arqueologia numa perspectiva histórica (Castañeda \& Matthews, 2008; Edgeworth, 2006; Hamilakis \&Anagnostopoulis, 2009; Hollowell \& Nicholas, 2008; Pyburn, 2008; 2009). Numa categorização entre as intersecções da etnografia e arqueologia, Castañeda (2008), fez uma distinção entre "etnoarqueologia" e "etnografias da arqueologia”. Na qual define a etnoarqueologia como o uso pelos arqueólogos de métodos etnográficos, destinados a produzir conhecimento que contribua para entender o passado como uma realidade material que é epistemologicamente mas não ontologicamente, separada do presente (Castañeda, 2008: 28). Outra das intersecções entre a arqueologia e etnografia é definida como "etnografias da arqueologia”, cujo método aplica a etnografia e a antropologia sociocultural para compreender o funcionamento político, histórico e discursivo da arqueologia nos contextos sociais contemporâneos (van der Linde, 2012: 25).

A maioria das etnografias de projectos arqueológicos focaliza-se no entorno dos sítios arqueológicos (Bartu, 200o; Castañeda, 2008: 37; Chiang, 2012; El-Haj, 2001; Meskell, 2005, "interface social" (Long, 2003) onde a multiplicidade de interpretações possibilita o desenvolvimento de etnografias arqueológicas através de métodos como a observação participante (Castañeda, 2008: 37). Os pontos fortes da etnografia arqueológica, são a sua reflexividade crítica, natureza holística, o seu carácter multitemporal e não presentista, envolvimento sensorial com o mundo, compromisso político e a sua concepção como prática colectiva, que transcende as fronteiras entre o investigador e os seus diversos públicos (van der Linde, 2012: 25).

A etnografia arqueológica não é simplesmente uma prática emergente de reaproximação da arqueologia social e da antropologia social, é um espaço interdisciplinar, transcultural, que ao nível da metodologia e da prática, envolve investigações multicêntricas, etnográficas e etno-históricas, como entrevistas formais, informais e observação participante (Hamilakis \& Anagnostopoulos, 2009: 67). Mais do que a reintrodução da etnografia em projectos arqueológicos, é um espaço transdisciplinar e transcultural de relacionamento, diálogo e crítica, entre investigadores e outros actores sociais centrado nos vestígios do passado (Hamilakis \& Anagnostopoulos, 2009: 67). A etnografia arqueológica pode incluir também as etnografias da prática arqueológica e dos arqueólogos, especialmente as maneiras pelas quais os conhecimentos arqueológicos são produzidos e as práticas arqueológicas são realizadas (Edgeworth, 2006). As etnografias arqueológicas perturbam as ontologias arqueológicas convencionais e os modos de pensar e da prática disciplinar (Hamilakis \& Anagnostopoulos, 2009: 71).

A observação participante desta investigação, consistirá no registo das dinâmicas dos grupos de interesse, obtidas pela observação e compreensão das relações entre as comunidades locais e os sítios arqueológicos. A par da observação participante, realizarei entrevistas semiestruturadas individuais e em grupo, gravadas por meios audiovisuais, por forma a capturar e transmitir a multivocalidade dessas duas paisagens patrimoniais, um documentário, um arquivo audiovisual e uma série de clips de filme das entrevistas com o objectivo de apresentar e divulgar os valores patrimoniais atribuídos aos sítios arqueológicos pelas comunidades locais.

A estratégia metodológica REAP a utilizar (cf. Low, 2002) envolve, um enfoque interpretativo e pretende produzir uma descrição das várias considerações acerca do fenómeno social em investigação. Esta estratégia pretende determinar os valores culturais e sociais atribuídos a estes sítios arqueológicos pelas comunidades locais. As metodologias supramencionadas, serão complementadas pela avaliação dos valores económicos a realizar nesta investigação com recurso às metodologias propostas por Klamer (Klamer, 2004). Nomeadamente o estudo de impacto do valor económico adicionado pelo processo de investigação, conservação e patrimonialização, 
gerado pelo retorno económico do investimento realizado no processo de estudo, conservação e valorização dos Sítios Pré-historicos de Arte Rupestre do Vale do Côa e de Siega Verde nos diversos sectores da economia. Estes projectos de arqueologia pública, serão investigados na relação dos diversos agentes, contextos e processos sociais, através da etnografia como componentes do processo e dinâmica da investigação arqueológica, base para processos interactivos entre arqueólogos, partes interessadas, público e intercâmbio transcultural de interpretações, reivindicações e significados do passado (Castañeda, 2008: 54).

\section{BIBLIOGRAFIA}

ALBERT, Marie-Theres (2012) - Perspectives of World Heritage: towards future-oriented strategies with the five 'Cs'. In ALBERT, Marie-Theres et al., eds. - Community Development through World Heritage. Paris: UNESCO World Heritage Centre, (World Heritage papers, 31), pp. 32-38.

APLIN, G. (2002) - Heritage identification:Conservation and management. Oxford: Oxford University Press.

AUSTRALIA ICOMOS (1979) - The Burra Charter. Disponível em: https://australia.icomos.org/publications/charters / [Acedido em 15 de Julho 2020].

AUSTRALIA ICOMOS (1988) - Guidelines to the BurraCharter: procedures for undertaking studies and reports. Disponível em: https://australia.icomos.org/wp-content/ uploads/Guidelines-to-the-Burra-Charter_-Procedures. pdf[Acedido em 15 Julho 2020].

AUSTRALIA ICOMOS (200o) - The Burra Charter: The Australia ICOMOS Charter for Places of Cultural Significance 1999, with associated guidelines and code on the ethics of co-existence in conserving significant places. Australia ICOMOS Inc. Available at: http://australia.icomos.org/wp-content/uploads/BURRA_CHARTER.pdf. [Acedido em 15 Julho 2020].

AUSTRALIA ICOMOS (2013) - Practice Note: Understanding and assessing cultural significance. Disponível online: https://australia.icomos.org/wp-content/uploads/ Practice-Note_Understanding-and-assessing-culturalsignificance.pdf [Acedido em 15 Julho 2020].

AVRAMI, E.; de la Torre, M; Mason, R., eds. (200o) - The Values and Benefits of Cultural Heritage Conservation: Research Report. Los Angeles: CA: Getty Conservation Institute.

BATTAINI-DRAGONI, G., ed. (2005) - Guidance on Heritage Assessment. Strasbour: Council of Europe.

BARTU, A. (200o) - Where is Catalhöyülk? Multiple sites in the construction of an archaeological site. In: HODDER, I. ed. - Towards a reflexive method in archaeology. The example at Catalhöyük. Cambridge and London: McDonald Institute for Archaeological Research and British Institute of Archaeology at Ankara, pp. 1010-109.

BYRNE, Denis, BRAYSHAW, H., IRELAND, T. (2003) Social Significance: A Discussion Paper. Second edition. Hurstville: New South Wales National Parks and Wildlife Service.

CASTAÑEDA, Q. E., MATTHEWS, C., eds. (2008) Ethnographic Archaeologies: Reflections on Stakeholders and Archaeological Practices. Lanham: MD: Altamira Press.

CASTAÑEDA, Q. E. (2008) - The 'ethnographic turn' in archaeology: research positioning and reflexivity in ethnographic archaeologies, In CASTAÑEDA, Q.; MATTEWS, C., eds. - Ethnographic Archaeologies: Reflections on Stakeholders and Archaeological Practices, Lanham MD: AltaMira Press, pp. 25-61.

CARTER, R. W.; BRAMLEY, R. (2002) - Defining Heritage Values and Significance for Improved Resource Management: An Application to Australian Tourism. International Journal of Heritage Studies 8:3, pp. 175-199.

CHIANG, M. (2012) - Memory Contested, Locality Transformed. Representing Japanese Colonial 'Heritage'. Archaeological Studies Leiden University 26, Leiden: Leiden University Press.

CONSELHO DA EUROPA (2005) - Convenção Quadro do Conselho da Europa Relativa ao Valor do Património Cultural para a Sociedade, Resolução da Assembleia da República n.ำ47/2008 de 12 de Setembro, Diário da República, 1.a série, $177,6640-6652$.

DARVILL, T. C. (1995) - Value systems in archaeology, In COOPER, M. A.; FIRTH, A. Firth; CARMAN, J.; WEATLEY, eds. - A Managing Archaeology, Routledge: London, pp. 40-50.

DE LA TORRE, M. (2002) - Assessing the Values of Cultural Heritage: Research Report. Los Angeles: The Getty Conservation Institute.

DE LA TORRE, M. (2013) - Values and Heritage Conservation. Heritage $\&$ Society 6:2, pp. 155-166.

DÍAZ-ANDREU, M. (2016a) - Arqueología, comunidad y valor social: un reto para el património arqueológico del siglo XX?. In DÍAZ-ANDREU, M; PASTOR PÉREZ, A; RUIZ, A., eds. - Arqueología y Comunidad. El valor social del patrimonio arqueológico en el siglo XX. Madrid: JAS Arqueología S.L.U, pp. 69-89.

DÍAZ ANDREU, M. (2016b) - Social values and local communities in World Heritage: a dream too far?' European Journal of Post-Classical Archaeologies [special section: M. Díaz-Andreu (ed.) World Heritage \& the Public], 6, pp. 193-212.

DÍAZ ANDREU, M. (2017) - Introduction: Heritage Values and the Public. Journal of Community Archaeology $\&$ Heritage 4.1, pp. 2-6. 
DÍAZ-ANDREU, M. (no prelo) - From Aesthetics to Economics. A History of Heritage Values.

DOUMAS, C. G. (2013) - Managing the Archaeological Heritage: The Case of Akrotiri, Thera (Santorini). Conservation and Management of Archaeological Sites 15:1, pp. 109-120.

EDGEWORTH, M. (2006) - Ethnographies of archaeological practice: cultural encounters, material transformations. Lanham MD: Altamira Press.

EL-HAJ, Nadia Abu (2001) - Facts on the Ground: Archaeological Practice and Territorial Self-Fashioning in Israeli Society. Chicago: University of Chicago Press.

ENGLISH HERITAGE (2006) - Conservation Principles for the Sustainable Management of the Historic Environment. First Stage Consultation. London: English Heritage.

ENGLISH HERITAGE (2008) - Conservation Principles. London: English Heritage.

GEURDS, Alexander (2007) - Grounding the Past: The Praxis Participatory Arcaheology in the Mixtexa Alta, Oaxaca, Mexico: Leiden: CNWS Publications.

HALL, C. M.; MACARTHUR, S. (1998) - Integrating Stakeholders into Heritage Management, Involving the Community, In Integrated Heritage Management: Principles and Practices, pp. 41-85. London: The Stationery Office.

HAMILAKIS, Y.; ANAGNOSTOPOULOS, A. (2009) Archaeological Ethnographies. Public Archaeology 8.2-3. Cambridge: Maney Publishing.

HERAS, C. V.; WIJFFELS, A.; CARDOSO, F.; VANDESANDE, A. SANTANA, M.; ORSHOVENVAN, J.; BALENVAN, K (2013) - A Value-Based Monitoring System to Support Heritage Conservation Planning. Journal of Cultural Heritage Management and Sustainable Development 3:2, pp. 130-147.

HALL, S. (1997) - Representation: Cultural Representations and Signifying Practices. London: Sage Publications.

HERAS, V.C.; WIJFFELS, A.; CARDOSO, F.; VANDESANDE, A.; SANTANA, M.; ORSHOVEN, J.; STEENBERGHEN, T.; VAN BALENS, K. (2013) - A value-based monitoring system to support heritage conservation planning. Journal of Cultural Heritage Management and Sustainable Development, 3: 2, pp. 130-147.

HERRMANN, JUDITH (2015) - Tracing change in World Cultural Heritage: the recognition of intangible heritage, Ph.D. Thesis, Faculté de l'aménagement, Université de Montréal, disponível online: https://papyrus.bib.umontreal.ca/xmlui/bitstream/handle/1866/14112/Herrmann Judith_2015These.pdf?sequence=2 (Acedido a 15 de Julho 2020).

HOLLOWELL, J.; NICHOLAS, G. (2008) - A Critical Assessment of Ethnography in Archaeology.In CASTAÑEDA, Q.; MATTEWS, C. eds. - Ethnographic archaeologies: reflections on stakeholders and archaeological practices, Lanham MD: AltaMira Press, pp.63-94.

HOLLOWELL, J.; NICHOLAS, G. (2009) - Using Ethnographic Methods to Articulate Community-Based Conceptions of Cultural Heritage Management. Public Archaeology, 8:2-3, pp. 141-16o.

JONES, S.; LEECH, S (2015) - Valuing the historic environment: A critical review of existing approaches to social value. London: Arts and Humanities Research Council.

JONES, S. (2017) - Wrestling with the Social Value of Heritage: Problems, Dilemmas and Opportunities, Journal of Community Archaeology \& Heritage, 4:1, pp. 23-37.

JOHNSTON, C.; CAIRNES, L.; EYLES, K.; JOHNSTON, C. (2006) - An Integrated Approach to Environment and Heritage Issues. Prepared for the Australian State of the Environment Committee. Canberra: Department of Environment and Heritage.

KLAMER, A. (2014) - The Values of Archaeological and Heritage Sites, Public Archaeology, 13:1 pp. 59-70.

LABADI, Sophia (2007) - Representations of the Nation and Cultural Diversity in Discourses on World Heritage. Journal of Social Archaeology, 7:2, pp. 147-170.

LABADI, Sophia (2013) - UNESCO, cultural heritage, and outstanding universal value: Value-based analyses of the World Heritage and Intangible Cultural Heritage Conventions. Lanham: Alta Mira Press.

LIPE, W. (1984) - Value and Meaning in Cultural Resources. In CLEERE, Henry, ed. - Approaches to the Archaeological Heritage. A Comparative Study of World Cultural Resource Management Systems. Cambridge: Cambridge University Press, pp. 1-11.

LONG, N. (2003) - An actor-oriented approach to development intervention'. In CRUZ, D.A., ed. - Rural life improvement in Asia. Report of an APO Seminar on Rural Life Improvement for Community Development held in Japan. Tokyo: Asian Productivity Organization.

LOW, S. M. (2002) - Anthropological-ethnographic methods for the assessment of cultural values in heritage conservation'. In DE LA TORRE, M., ed. - Assessing the values of cultural heritage, Los Angeles: Getty Conservation Institute, pp. 31-49.

LUNG, D. P. Y.; DISTEFANO, L.; LEE, H. Y.; WONG, D. T. Y. (2007) - Interpreting the Significance of Heritage sites. In ENGLEHART, R., ed. - Englehardt Asia Conserved: Lessons Learned from the UNESCO Asia-Pacific Heritage Awards for Cultural Heritage Conservation (200O-2004), Bangkok: UNESCO, pp. 21-27.

MARSHALL, Y., (2002) - What is community archaeology? World Archaeology 34:2, pp. 211-219.

MASON, R. (1999) - Economics and Heritage Conservation: Concepts Values and Agendas for Research: A Meeting 
Organized by the Getty Conservation Institute Economics and Heritage Conservation. Los Angeles: J. Paul Getty Trust, pp. 2-18.

MASON, R.; AVRAMI, E. (2002) - Heritage values and challenges of conservation planning', In TEUTONICO J.M.; PALUMBO, G. eds. - Management Planning for Archaeological Sites: An International Workshop. Los Angeles: The Getty Conservation Institute, pp. 13-26.

MASON, R. (2002a) - Assessing Values in Conservation Planning: Methodological Issues and Choices. Assessing the Values of Cultural Heritage. Los Angeles: The Getty Conservation Institute.

MASON, R. (2002b) - Assessing values in conservation planning. In DE LA TORRE, M. ed. - Assessing the Values of Cultural Heritage, Los Angeles: The Getty Conservation Institute, pp. 5-30.

MASON, R. (2006) - Theoretical and Practical Arguments for Values-Centered Preservation". CRM: The Journal of Heritage Stewardship 3: 2, pp 21-48.

MASON, R. (2008a) - Assessing Values in Conservation Planning. In FAIRCLOUGH, G.; HARRISON, R.; JAMESOSN, J.H.; SCHOFIELD, J., eds. - The Heritage Reader. New York: Routledge, pp. 99-124.

MASON, R. (2008b) - Be interested and beware: Joining economic valuation and heritage conservation. International Journal of Heritage Studies, 14: 4, pp. 303-318.

MATARASSO, F. (1997) - Use or Ornament? The Social Impact of Participation in the Arts. Comedia, Bournes Green, Stroud.

MYDLAND, L.; GRAHN, W. (2012) - Identifying Heritage Values in Local Communities'. International Journal of Heritage Studies 18:6, pp. 564-587.

MILLS, J.; BONNER, A.; FRANCIS, K. (2006) - The development of constructivist grounded theory'. International Journal of Qualitative Methods 5:1, pp 1-10.

MESKELL, L.; PELS, P. eds. (2005) - Embedding Ethics. Oxford: Berg.

MESKELL, L. (2007) - Falling walls and mending fences. Archaeological ethnograph in the Limpopo'. Journal of Social Archaeology 33 :2, pp, 383-40o.

OKAMURA, K. (2010) - A consideration of heritage values in contemporary society'. In SMITH, G. S.; MESSENGER, P. M.; SODERLAND, H. A., eds - Heritage Values in Contemporary Society. New York: Routledge.

PARKER, S. (2002) - Neighbourhood Renewal and Social Inclusion: The Role of Museums, Libraries and Archives. London: Museums, Libraries and Archives Council.

PEARSON, M.; SULLIVAN, S. (1995) - Looking after Heritage Places: the Basics of Heritage Planning for Managers, Landowners and Administrators. Carlton, Victoria: Melbourne University Press.
PERSON, P. E. (200o) - Community Impact of Science Centers: Is There Any? Curator'. The Museum Journal 43:1, pp. 9-17.

POULIOS, I. (2010) - Moving Beyond a 'Values-Based Approach' to Heritage Conservation'. Conservation and Management of Archaeological Sites 12:2, pp. 170-185.

PYBURN, K.A. (2009) - Practising Archaeology-As if it Really Matters. Public Archaeology: Archaeological Ethnographies 8, pp. 161-175.

PYBURN, K.A (2008) - Archaeology as Activism. The Pageantry of Archaeology. In MATTEWS, C.; CASTANESA, Q. eds. - The Public Meanings of the Archaeological. Walnut Creek: Altamira Press.

RIEGL, Alois (2013) - O Culto Modeno dos Monumentos de Alois Riegl. Lisboa: Edições 70.

RUSSELL, R.; WINKWORT, K. (2001) - Significance: A Guide to Assessing the Significance of Cultural Heritage $\mathrm{Ob}$ jects and Collections. Canberra. Heritage Collections Council.

SANDELL. R. (1988) - Museums as Agents of Social Inclusion'. Museum Management and Curatorship 17:4, pp. 63-74.

SHEPPARD, B. (200o) - Do Museums Make a difference? Evaluating Programs for Social Change'. Curator 43:1, pp. 63-74.

Slayter, R.O. (1983) - The Origin and Evolution of the World Heritage Convention. Ambio 12 3:4, pp. 138-140.

SMITH, Laurajane (2004) - Archaeological theory and the politics of cultural heritage. London. New York: Routledge.

SORENSEN, S.M.L.; CARMAN, J. (2009) - Heritage Studies: Methods and Approaches. London; New York: Routledge.

TAINTER, Joseph A.; LUCAS, G. John (1983) - Epistemology and the significance concept. American Antiquity 48:4, pp. 707-719.

TAYLOR, K. (2004) - Cultural Heritage Management: A Possible Role for Charters and Principles in Asia. International Journal of Heritage Studies 10:5, pp. 417-433.

TEUTONICO, J.; PALUMBO, G. (2002) - Management planning for archaeological sites: an international workshop organized by the Getty Conservation. Los Angeles: The Getty Conservation Institute.

TRUSCOTT, M.; YOUNG, D. (2000) - Revising the Burra Charter. Conservation and Management of Archaeological Sites 4:2, pp. 101-116.

UNESCO WHC. (2007) - Thirty-first session Christchurch, New Zealand. Disponível online em: https://whc. unesco.org/archive/2007/whco7-31com-24e.pdf [Accesso 15 de Julho 2020].

UNESCO (2017) - Orientações Técnicas para a Aplicação da Convenção do Património Mundial. Disponível on line 
em: http://whc.unesco.org/en/guidelines/ [Acedido em 15 Julho 2020].

VAN DER LINDE, S.J. (2012) - Digging holes abroad. An ethnography of Dutch Archaeological Research Projects Abroad. Leiden: Leiden University Press.

WATERTON, E.; SMITH, L.; CAMPBELL, G. (2006) - The utility of discourse analysis to heritage studies: The Burra Charter and social inclusion. International Journal of Heritage Studies 12:4, pp. 339-355. 



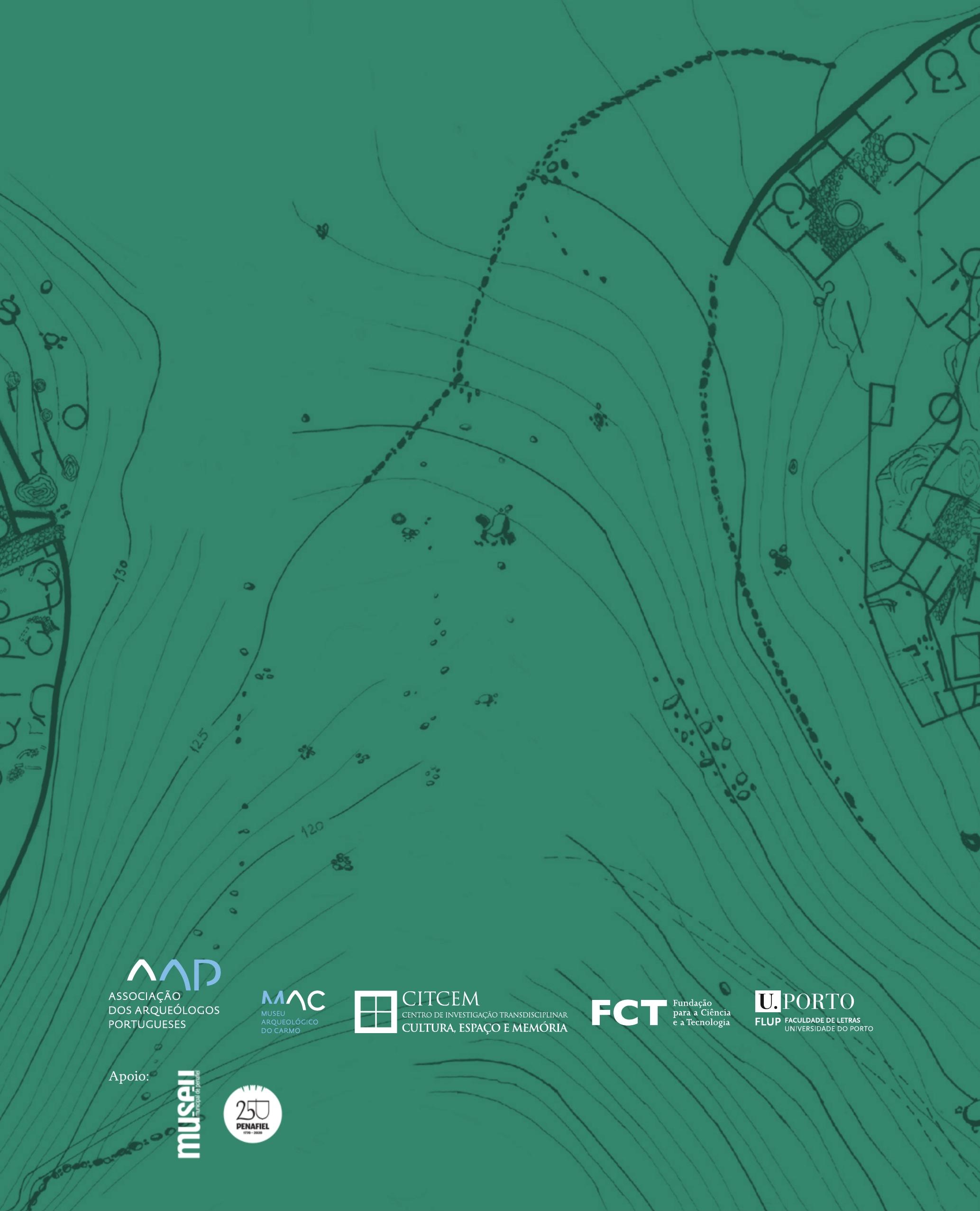

